\title{
Adiponectin inhibits the differentiation and maturation of osteoclasts via the mTOR pathway in multiple myeloma
}

\author{
ZHAOYUN LIU, HUI LIU, YANQI LI, YANGYANG WANG, RUI XING, FU MI, CHENHUAN XIANG and RONG FU \\ Department of Hematology, Tianjin Medical University General Hospital, Tianjin 300052, P.R. China
}

Received June 2, 2019; Accepted December 10, 2019

DOI: $10.3892 /$ ijmm.2020.4475

\begin{abstract}
The present study sought to investigate the correlation between adipose cytokines (visfatin, leptin and adiponectin) and markers of multiple myeloma bone disease, and to determine the effects and mechanism of action of adiponectin on the differentiation and maturation of osteoclasts in multiple myeloma (MM). The levels of visfatin, leptin and adiponectin were measured. Their association with the indices of myeloma tumor load and bone disease were analyzed. Reverse transcription-quantitative PCR was used to detect the expression of receptor activator of nuclear factor- $\kappa \mathrm{B}$ ligand (RANKL), osteoclast associated Ig-like receptor (OSCAR), tartrate-resistant acid phosphatase (TRAP) and Cathepsin K genes. Flow cytometry was used to detect the expression of adiponectin receptor 1 (AdipoR1) and the phosphorylation of the mechanistic target of rapamycin kinase (mTOR) pathway-associated proteins mTOR and eukaryotic translation initiation factor 4E-binding protein (4EBP1). There were no significant correlations among leptin, visfatin and the indexes of myeloma tumor load and bone disease. Serum adiponectin levels were significantly lower in patients with newly diagnosed multiple myeloma compared with healthy volunteers $(12.37 \pm 3.13$ vs. $13.80 \pm 0.95 ; \mathrm{P}<0.05)$. The number of mature osteoclasts in the adiponectin group was lower compared with in the control group. Adiponectin also inhibited the mRNA expression of the osteoclast-associated factors RANKL, OSCAR, TRAP and Cathepsin K. Comparison between the non-adiponectin group and the adiponectin group revealed
\end{abstract}

Correspondence to: Professor Rong Fu, Department of Hematology, Tianjin Medical University General Hospital, 154 Anshan Street, Heping, Tianjin 300052, P.R. China

E-mail: florai@sina.com

Abbreviations: CTX, carboxy-terminal cross-linking telopeptide of type I collagen; ISS, International Staging System; MBD, multiple myeloma bone disease; MM, multiple myeloma; OCN, osteocalcin; PINP, procollagen I amino-terminal propeptide; TRAP, tartrate-resistant acid phosphatase

Key words: adiponectin, osteoclasts, mechanistic target of rapamycin kinase pathway, multiple myeloma that adiponectin increased the expression of AdipoR1 on the surface of osteoclast precursor cells $(26.21 \pm 4.27 \%$ vs. $29.86 \pm 6.23 \% ; \mathrm{P}<0.05)$ and reduced the expression of phosphorylated (p-)mTOR $(7.89 \pm 1.00 \%$ vs. $5.91 \pm 1.26 \%$; $\mathrm{P}<0.05)$ and p-4EBP1 $(26.78 \pm 5.00 \%$ vs. $22.49 \pm 4.24 \%$; $\mathrm{P}<0.05)$. The p-mTOR and p-4EBP1 levels in the adiponectin + MHY1485 (an mTOR signaling pathway-specific agonist) group were significantly higher compared with those in the adiponectin group. It was revealed that adiponectin may inhibit osteoclast differentiation and maturation via the mTOR pathway. In conclusion, adiponectin inhibits the differentiation and maturation of osteoclasts by increasing the expression of AdipoR1 and reducing the phosphorylation levels of mTOR and 4EBP1 in patients with MM.

\section{Introduction}

Multiple myeloma (MM) is a hematological malignancy of terminally differentiated plasma cells. Myeloma bone disease (MBD) is the most common complication in patients with MM (1). Adipose cytokines including visfatin, leptin and adiponectin have been implicated in the stimulation or inhibition of tumor cell growth (2-5). For example, in a prospective study of 174 patients with MM and 348 controls (6), adiponectin was revealed to be associated with an increased MM risk. In contrast, Medina et al (7) demonstrated that adiponectin had an anti-proliferative effect on MM cells that was mediated by the protein kinase A/adenosine monophosphate-activated protein kinase (AMPK) signaling pathway. Adiponectin also was revealed to prevent MBD in a mouse myeloma model (8).

Little is known about the impact of adiponectin on bone disease induced by MM. To study this question, the present study aimed to determine the concentrations of visfatin, leptin and adiponectin in the serum and bone marrow and elucidate whether correlations exist between these concentrations and bone disease in patients with MM.

Osteoclasts are large multinucleated cells $(9,10)$ that are derived from tartrate-resistant acid phosphatase (TRAP)-positive monocyte-osteoclast precursor cells [mostly cluster of differentiation 14 (CD14) ${ }^{+}$mononuclear cells (11)] through the action of receptor activator of nuclear factor- $\kappa \mathrm{B}$ ligand (RANKL) and macrophage colony-stimulating factor (M-CSF). Osteoclast activation is associated with the development of MBD (12). For this reason, the present study 
investigated the effects of adiponectin on the differentiation and maturation of osteoclasts in MM.

Adiponectin exerts its functions by binding to adiponectin receptor (AdipoR)1 and AdipoR2. The magnitude of the effects of adiponectin on physiological functions in tissues is directly associated with receptor expression levels (13). AdipoR1 is expressed significantly higher in osteoclasts compared with AdipoR2, suggesting that AdipoR1 has a higher affinity for this receptor isoform (14). Cell growth and metabolism also are regulated by mechanistic target of rapamycin kinase (mTOR), which integrates nutrient, energy and oxygen level information. Previous studies have revealed that the mTOR pathway may be involved in the generation of osteoclasts and affect their bone resorption function (15) Walker et al (16) reported that adiponectin absence coincided with active AMPK/mTOR signaling in adiponectin knockout hepatocellular carcinoma cells, which indicates that mTOR lies downstream of adiponectin. However, it remains unclear how AdipoR1, mTOR and its downstream effector molecule eukaryotic translation initiation factor 4E-binding protein (4EBP1) are involved in the effect of adiponectin on the differentiation and maturation of osteoclasts in patients with MM. To study this question, flow cytometry was used to detect the expression of AdipoR1 on the surface of osteoclast precursor cells and the phosphorylation of mTOR and 4EBP1.

\section{Materials and methods}

Study subjects. Subjects were recruited from the Hematology Department of Tianjin Medical University General Hospital (Tianjin, China). The present study was ethically approved by the Ethics Committee of the Tianjin Medical University. Written informed consent was obtained from all patients for the publication of this report and any accompanying images. Bone marrow and peripheral blood were collected from 39 newly diagnosed patients with MM (including 24 men and 15 women; median age, 56 years; range, $46-72$ years), according to the International Myeloma Working Group (17). Peripheral blood from normal controls were collected from 20 age-matched healthy volunteers. Bone marrow mononuclear cells (BMMNCs) were extracted from 32 newly diagnosed patients with MM. The diagnoses of patients with MM were made according to the International Myeloma Workgroup criteria. X-ray images were used to stage disease prior to treatment. Bone disease was graded as follows: Stage A, no osteolytic lesions or osteoporosis alone; stage $\mathrm{B}$, one to three osteolytic lesions; and stage $\mathrm{C}$, more than three osteolytic lesions and/or a pathological fracture (18). Patients with MM were classified using the International Staging System (ISS). ISS stage I was defined as serum $\beta 2$-microglobulin levels $<3.5 \mathrm{mg} / \mathrm{l}$ and serum albumin levels $>3.5 \mathrm{~g} / \mathrm{dl}$. ISS stage III was defined as serum $\beta 2$-microglobulin level $>5.5 \mathrm{mg} / \mathrm{l}$, independent from serum albumin level. ISS stage II included patients who did not fulfill the criteria for stages I and II (19).

Enzyme-linked immunosorbent assay (ELISA). Serum and bone marrow were collected prior to treatment. Sera were centrifuged at $1,000 \times \mathrm{g}$ for $10 \mathrm{~min}$ at room temperature and then stored at $-80^{\circ} \mathrm{C}$ until use. Concentrations of visfatin, leptin and adiponectin were measured using commercially available ELISA kits (adiponectin (cat. no. SEA605Hu), visfatin (cat. no. SEA638Hu) and leptin (cat. no. SEA084Hu) (all Uscn Life Sciences, Inc., Wuhan, China) according to the manufacturer's protocol.

Electrochemiluminescence immunoassay. The serum levels of carboxy-terminal cross-linking telopeptide of type I collagen (CTX), osteocalcin $(\mathrm{OCN})$ and procollagen I amino-terminal pro-peptide (PINP) were analyzed using kits (cat. no. COBASE601) from Roche Diagnostics $\mathrm{GmbH}$ (Mannheim, Germany) according to the manufacturer's protocol.

Differentiation and identification of osteoclasts. In brief, BMMNCs were isolated from patients with MM and cultured in $\alpha$-Minimum Essential Medium containing $10 \%(\mathrm{v} / \mathrm{v})$ fetal bovine serum (Gibco; Thermo Fisher Scientific, Inc., Waltham, MA, USA), $50 \mathrm{ng} / \mathrm{ml}$ M-CSF (Miltenyi Biotec, Inc., Cambridge, MA, USA) and $100 \mathrm{ng} / \mathrm{ml}$ RANKL (Miltenyi Biotec, Inc.). Recombinant human full-length adiponectin (PeproTech, Inc., Rocky Hill, NJ, USA) was dissolved in water at a concentration of $1.0 \mathrm{mg} / \mathrm{ml}$ and then diluted with $0.1 \%$ bovine serum albumin to a final concentration of $0.1 \mathrm{mg} / \mathrm{ml}$. It then was stored at -20 to $-80^{\circ} \mathrm{C}$ until use. BMMNCs were cultured for 14 days in the presence of $10 \mu \mathrm{g} / \mathrm{ml}$ adiponectin, following which the osteoclasts were identified using TRAP staining at $37^{\circ} \mathrm{C}$ for 5 min using a commercial TRAP staining kit (Sigma-Aldrich;). The number of TRAP-positive multinuclear ( $>3$ nuclei) cells in each well were counted.

Reverse transcription-quantitative PCR (RT-qPCR). Total RNA was extracted using TRIzol reagent (Tiangen Biotech Co., Ltd., Beijing, China). The quality of RNA samples was assessed spectrophotometrically (Bio-Rad Laboratories, Inc., Hercules, CA, USA). Finally, the extracted RNA was dissolved in $20 \mu \mathrm{l}$ diethylpyrocarbonate-treated water and cDNA was synthesized using a TIANScript RT kit (Tiangen Biotech Co., Ltd.), according to the manufacturer's protocol: DNA removal reaction at $42^{\circ} \mathrm{C}$ for $3 \mathrm{~min}$, $\mathrm{RT}$ reaction at $42^{\circ} \mathrm{C}$ for $15 \mathrm{~min}$, then $95^{\circ} \mathrm{C}$ for $3 \mathrm{~min}$. RNA levels were quantified by RT-qPCR using a Bio-Rad iQ5 Real-time system (Bio-Rad Laboratories, Inc.) and the thermocycling conditions were as follows: $95^{\circ} \mathrm{C}$ for $30 \mathrm{sec}, 95^{\circ} \mathrm{C}$ for $5 \mathrm{sec}$, then annealing temperature for $30 \mathrm{sec}$, with a total of 45 cycles. The levels of RNA were determined using the $2^{-\Delta \Delta \mathrm{Cq}}$ method using $\beta$-actin as a control (20). SYBR Green (Tiangen Biotech Co., Ltd.) was used as a double-strand DNA-specific dye. Primers sequences are presented in Table I.

Flow cytometric analysis. Flow cytometric analysis was conducted using a CytoFlex flow cytometer and CytExpert Pro analysis software 2.0 (Beckman Coulter, Inc., Brea, CA, USA). The side scatter area represent the relative measures of complexity (21). According to a previous study by Sorensen et al (22), CD14 is the specific marker of the osteoclasts precursor derived from $\mathrm{CD}_{1} 4^{+}$monocytes cultured with M-CSF and RANKL. Thus, CD14-positive cells are osteoclasts precursor cells. To detect AdipoR1 expression, osteoclast precursor cells were labeled with anti-CD14 (BD Pharmingen; BD Biosciences, Franklin Lakes, NJ, USA; cat. no. 562691) and anti-AdipoR1 (Abcam; cat. no. ab126611) for $15 \mathrm{~min}$ at room temperature. Phosphorylation of mTOR and 4EBP1 was 
Table I. Primer sequences.

\begin{tabular}{|c|c|c|}
\hline Target & Sense and antisense sequences & Annealing temperature, ${ }^{\circ} \mathrm{C}$ \\
\hline \multicolumn{3}{|c|}{ RANKL } \\
\hline $\mathrm{F}$ & 5'-ATATCGTTGGATCACAGCACATCAGAG-3' & 58.7 \\
\hline $\mathrm{R}$ & 5'-TGTCGGTGGCATTAATAGTGAGATGAG-3' & \\
\hline \multicolumn{3}{|c|}{ OSCAR } \\
\hline $\mathrm{F}$ & 5'-GTTACCGCTGCTGCTACCGAAG-3' & 59.2 \\
\hline $\mathrm{R}$ & 5'-GCGCAGGCTCACGTTGGC-3' & \\
\hline \multicolumn{3}{|l|}{ TRAP } \\
\hline $\mathrm{F}$ & 5'-ATGACCACCTTGGCAATGTCTCTG-3' & 60.4 \\
\hline $\mathrm{R}$ & 5'-AGGCTGCTGGCTGAGGAAGTC-3' & \\
\hline \multicolumn{3}{|c|}{ Cathepsin $\mathrm{K}$} \\
\hline $\mathrm{F}$ & 5'-CCATCCATAACCTTGAGGCTTCTCTTG-3' & 61.3 \\
\hline $\mathrm{R}$ & 5'-CCAGTCATCTTCTGAACCACCTCTTC-3' & \\
\hline \multicolumn{3}{|c|}{ GAPDH } \\
\hline $\mathrm{F}$ & 5'-CAGGAGGCATTGCTGATGAT-3' & 59.8 \\
\hline $\mathrm{R}$ & 5'-GAAGGCTGGGGCTCATTT-3' & \\
\hline
\end{tabular}

determined as follows: Anti-CD14 antibodies (BD Pharmingen; BD Biosciences; cat. no. 562691) were incubated with cells at room temperature for $15 \mathrm{~min}$. Cells were washed with phosphate buffered saline, then fixed at room temperature for $5 \mathrm{~min}$ and permeabilized for $30 \mathrm{~min}$ using the Fixation/Permeabilization Solution kit (BD Biosciences) according to the manufacturer's protocol. mTOR signaling pathway-specific agonist (MHY1485) was added $(10 \mu \mathrm{M} ; 4 \mathrm{~h})$ at $37^{\circ} \mathrm{C}$ after 14 days in the presence of $10 \mu \mathrm{g} / \mathrm{ml}$ adiponectin to further determine whether the effects of adiponectin may be reversed. Anti-mTOR (BD Phosflow; BD Biosciences; cat. no. 563489) or anti-4EBP1 antibody (BD Phosflow; BD Biosciences; cat. no. 560285) then were added for $20 \mathrm{~min}$ at room temperature.

Statistical analysis. SPSS 21.0 software (IBM Corp., Armonk, NY, USA) was used for statistical analysis. All results are expressed as the mean $\pm \mathrm{SD}$, median and quartile range. An unpaired Student's t-test and one-way analysis of variance with the LSD post hoc test were used to analyze the significance of differences between groups. A non-parametric test (Mann-Whitney U test) was used if the data were not normally distributed. The correlation between visfatin, leptin and adiponectin and CTX was performed using a Pearson's test. A Spearman's test was used to determine the correlation between visfatin, leptin or adiponectin, and OCN or PINP. $\mathrm{P}<0.05$ was considered to indicate a statistically significant difference.

\section{Results}

Levels of adiponectin are decreased in newly diagnosed patients with MM. Clinical characteristics of the patients are presented in Table II. Adiponectin levels in the serum from patients with MM were significantly lower compared with in normal controls $(12.37 \pm 3.13 \mathrm{ng} / \mathrm{ml}$ vs. $13.80 \pm 0.95 \mathrm{ng} / \mathrm{ml}$; $\mathrm{P}=0.045)$. Visfatin levels were significantly higher in the serum from patients with MM compared with the control $(102.76 \pm 90.41 \mathrm{ng} / \mathrm{ml}$ vs. $22.55 \pm 21.41 \mathrm{ng} / \mathrm{ml} ; \mathrm{P}<0.001)$. There was no significant difference between the level of leptin in patients with MM and the normal controls (Table II; Fig. 1).

Level of adiponectin is associated with ISS and bone disease stage in MM. The present study compared the levels of adiponectin according to the stage of ISS and bone disease. The serum levels of adiponectin in patients with stage I/II MM was significantly higher compared with in patients with stage III MM ( $\mathrm{P}<0.05$; Table III). However, the serum and bone marrow levels of adiponectin in MBD stage A were significantly higher compared with those in stages $\mathrm{B}$ or $\mathrm{C}$ $(\mathrm{P}<0.05$; Table IV). No significant differences in visfatin or leptin levels were correlated with stage of ISS or bone disease (Tables III and IV).

OCN is positively correlated and CTX is negatively correlated with the level of adiponectin in patients with MM. The present study determined the correlation between serum levels of visfatin, leptin and adiponectin and measures of MM load ( $\beta_{2}$-microglobulin, plasma cell percentage in bone marrow, serum creatinine and LDH) or serum markers of bone disease (OCN, CTX and PINP). Adiponectin levels significantly correlated negatively with CTX $(r=-0.339, \mathrm{P}<0.05)$. Positive significant correlations were identified for OCN ( $\mathrm{r}=0.394$, $\mathrm{P}<0.05$; Table $\mathrm{V}$ and Fig. 2). The levels of visfatin and leptin were not significantly correlated with MM load or serum markers.

Adiponectin inhibits osteoclast differentiation and maturation. BMMCs were cultured with RANKL and M-CSF for 
Table II. Profiles of patients with MM enrolled in the present study.

\begin{tabular}{|c|c|c|c|c|c|c|c|c|c|c|c|c|}
\hline \multirow[b]{2}{*}{ Group } & \multirow[b]{2}{*}{ Patient (n) } & \multicolumn{2}{|c|}{ Sex } & \multirow{2}{*}{$\begin{array}{c}\text { Age (years), } \\
\text { median (range) }\end{array}$} & \multicolumn{2}{|c|}{ ISS } & \multicolumn{3}{|c|}{ Type of MM } & \multirow{2}{*}{$\begin{array}{c}\text { Visfatin } \\
(\mathrm{ng} / \mathrm{ml}, \overline{\mathrm{x}} \pm \mathrm{s})\end{array}$} & \multirow{2}{*}{$\begin{array}{c}\text { Leptin } \\
(\mathrm{ng} / \mathrm{ml}, \overline{\mathrm{x}} \pm \mathrm{s})\end{array}$} & \multirow{2}{*}{$\begin{array}{l}\text { Adiponectin } \\
(\mathrm{ng} / \mathrm{ml}, \overline{\mathrm{x}} \pm \mathrm{s})\end{array}$} \\
\hline & & Male & Female & & $\mathrm{I} / \mathrm{II}$ & III & $\operatorname{IgG}$ & $\operatorname{IgA}$ & $\kappa \lambda$ & & & \\
\hline MM (serum) & 39 & 24 & 15 & $63(47-83)$ & 8 & 31 & 22 & 8 & 81 & $1102.76 \pm 90.41^{\mathrm{a}}$ & $0.21 \pm 0.11$ & $12.37 \pm 3.13^{\mathrm{a}}$ \\
\hline Control & 20 & 11 & 9 & $67(57-75)$ & & & & & & $22.55 \pm 21.41$ & $0.21 \pm 0.13$ & $13.80 \pm 0.95$ \\
\hline
\end{tabular}

${ }^{\mathrm{a}} \mathrm{P}<0.05$ vs. the control group. MM, multiple myeloma; Ig, immunoglobulin; ISS, International Staging System; $\overline{\mathrm{x}} \pm \mathrm{s}, \mathrm{mean} \pm \mathrm{SD}$.

Table III. Levels of visfatin, leptin and adiponectin in patients with different ISS phase multiple myeloma.

\begin{tabular}{lcccc}
\hline ISS & Patient (n) & Visfatin (ng/ml) & Leptin (ng/ml) & Adiponectin (ng/ml) \\
\hline I/II & 8 & $60.66 \pm 54.68$ & $0.20 \pm 0.05$ & $14.47 \pm 1.29^{\mathrm{a}}$ \\
III & 31 & $113.62 \pm 95.19$ & $0.21 \pm 0.12$ & $11.83 \pm 3.24$ \\
\hline
\end{tabular}

${ }^{a} \mathrm{P}<0.05$ vs. the III group. Data presented as the mean \pm SD. ISS, International Staging System.

Table IV. Levels of visfatin, leptin and adiponectin in different multiple myeloma bone disease stages.

\begin{tabular}{lcccc}
\hline Bone disease & Patient $(\mathrm{n})$ & Visfatin $(\mathrm{ng} / \mathrm{ml})$ & Leptin $(\mathrm{ng} / \mathrm{ml})$ & Adiponectin $(\mathrm{ng} / \mathrm{ml})$ \\
\hline Stage A & 8 & $55.38 \pm 49.57$ & $0.17 \pm 0.05$ & $14.36 \pm 2.32^{\mathrm{a}}$ \\
Stage B/C & 26 & $114.98 \pm 95.01$ & $0.22 \pm 0.12$ & $11.86 \pm 3.13$ \\
\hline
\end{tabular}

${ }^{\mathrm{a}} \mathrm{P}<0.05$ vs. the stage $\mathrm{B} / \mathrm{C}$ group. Data presented as the mean $\pm \mathrm{SD}$.
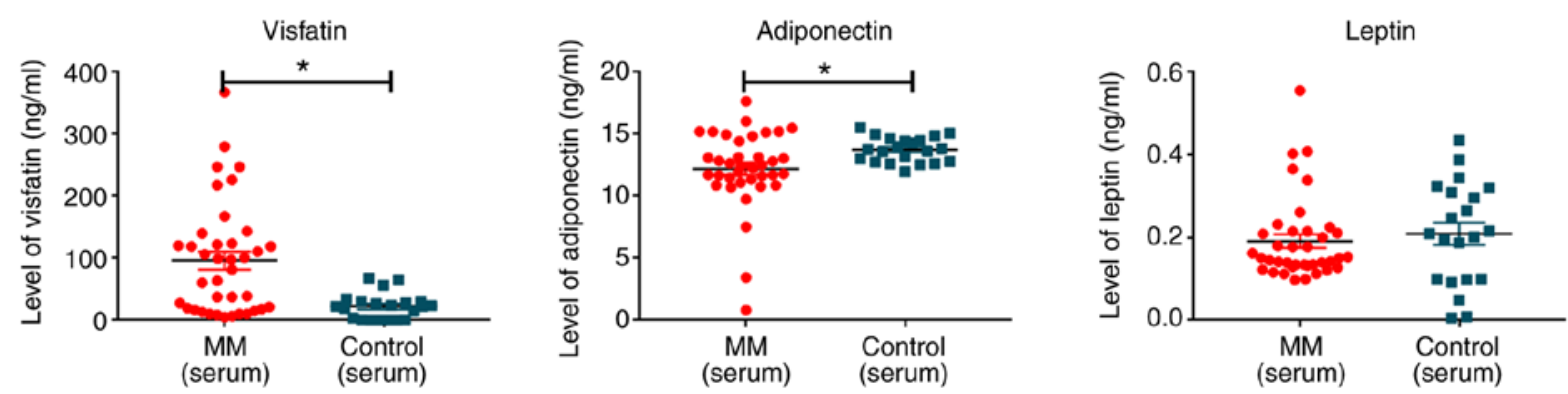

Figure 1. Visfatin, leptin, and adiponectin levels in newly diagnosed patients with $\mathrm{MM}$. ${ }^{\mathrm{P}}<0.05$ with comparisons shown by lines. MM, multiple myeloma.

14 days, following which TRAP staining was performed. Osteoclasts were observed in each of the groups, but the number of osteoclasts in the adiponectin group were significantly lower compared with that in the control group $(\mathrm{P}<0.05$; Fig. 3). RT-qPCR was also performed to determine the mRNA expression levels of the osteoclast specific factors RANKL, OSCAR, TRAP and Cathepsin K. Expression levels for all factors were significantly lower in the adiponectin group compared with in the control group $(\mathrm{P}<0.05$; Fig. 4).

Adiponectin upregulates AdipoRl expression on osteoclast precursors. To further investigate the mechanism of action of adiponectin on the differentiation and maturation of $\mathrm{MM}$ osteoclasts, the levels of the cell surface expression of AdipoR1 on osteoclast precursor cells $\left(\mathrm{CD} 14^{+}\right.$cells) was determined using flow cytometry. The levels of AdipoR1 in the adiponectin group were significantly higher compared with in the control group $(\mathrm{P}<0.05$; Fig. 5).

Adiponectin downregulates the phosphorylation of mTOR and $4 E B P 1$. The combination of RANK and RANKL have been revealed to activate the mTOR pathway, which serves an important function in the differentiation and maturation of osteoclasts (23). To determine the effect of adiponectin on this pathway, the phosphorylation of mTOR and its downstream signaling molecule 4EBP1 were measured. The 
Table V. Correlations of visfatin, leptin and adiponectin levels with indices of bone disease (OCN, CTX and PINP).

\begin{tabular}{lccc}
\hline & Visfatin & Leptin & Adiponectin \\
\hline OCN & & & \\
r-value & -0.314 & 0.122 & 0.394 \\
P-value & 0.071 & 0.491 & 0.013 \\
CTX & & & \\
r-value & -0.045 & 0.011 & -0.339 \\
P-value & 0.799 & 0.949 & 0.035 \\
PINP & & & \\
r-value & 0.221 & -0.322 & -0.189 \\
P-value & 0.208 & 0.063 & 0.285 \\
\hline
\end{tabular}

CTX, carboxy-terminal cross-linking telopeptide of type I collagen; OCN, osteocalcin; PINP, procollagen I amino-terminal propeptide.
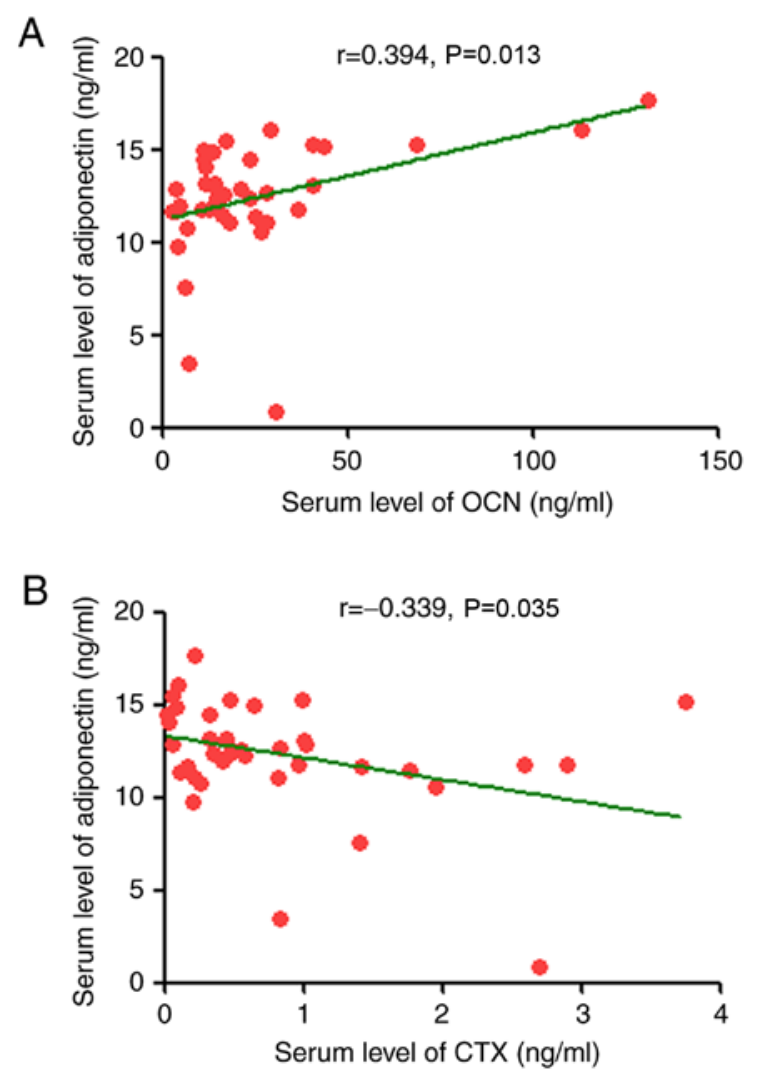

Figure 2. Correlation between adiponectin, and either OCN or CTX levels in patients with multiple myeloma. (A) Serum level of adiponectin is positively correlated with OCN levels. (B) Serum level of adiponectin is negatively correlated with CTX levels. OCN, osteocalcin; CTX, carboxy-terminal cross-linking telopeptide of type I collagen.

phosphorylation levels of mTOR and 4EBP1 were significantly lower in the adiponectin group compared with in the control group ( $\mathrm{P}<0.05$; Fig. 6). Additionally, a mTOR signaling pathway-specific agonist (MHY1485) was used to further determine whether the effects of adiponectin may be reversed. The results revealed that the levels of p-mTOR and p-4EBP1 in the adiponectin + MHY1485 group were significantly higher
A

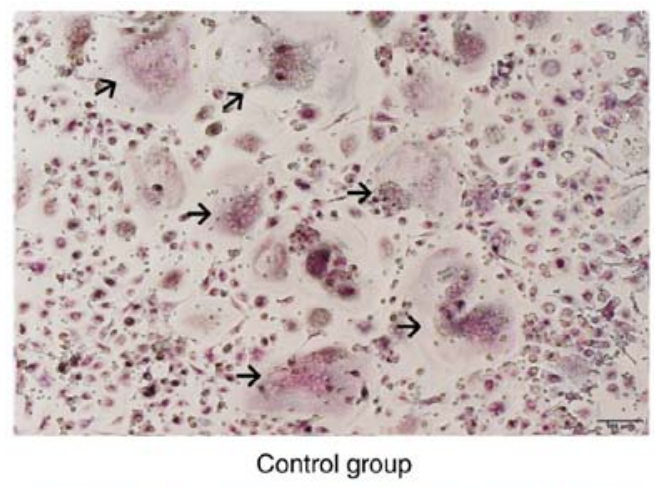

B

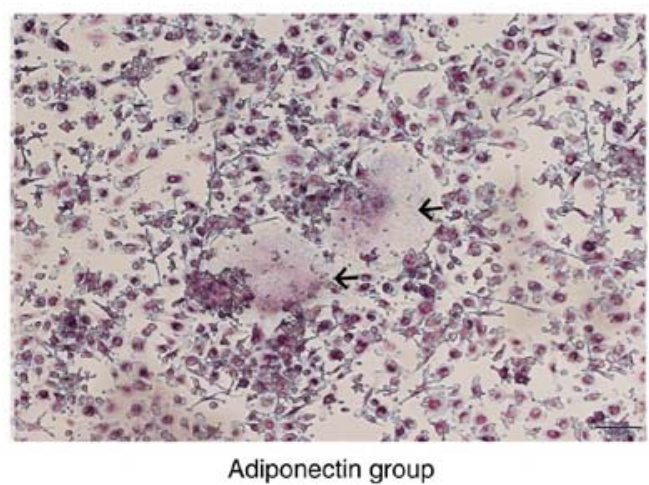

C

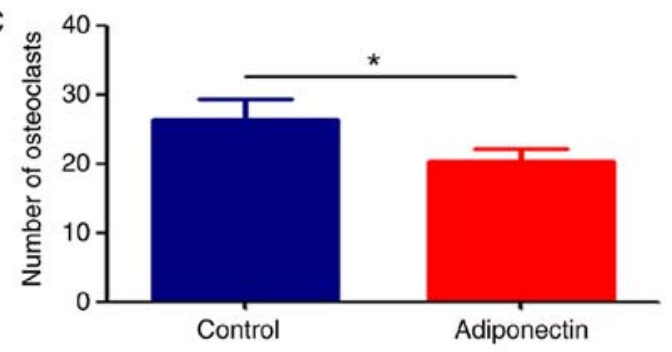

Figure 3. Adiponectin inhibits osteoclast differentiation and maturation. TRAP staining was performed in (A) the control group and (B) the adiponectin-treated group (original magnification, x100). (C) Quantified number of TRAP-positive multinucleated cells. " $\mathrm{P}<0.05$ with comparisons shown by lines. TRAP, tartrate-resistant acid phosphatase.

compared with that in the adiponectin alone group $(\mathrm{P}<0.05$; Fig. 6). It revealed that adiponectin may inhibit osteoclast differentiation and maturation via the mTOR pathway.

\section{Discussion}

Previous studies have revealed that obesity is a risk factor for MM (24) and MBD due to the associated increase in the release of adipocytokines (25). The present study studied the association between markers of MBD and the adipocytokines visfatin, leptin and adiponectin in patients with MM. Visfatin is known to facilitate the proliferation of pre-B cells and digestive system neoplasms $(5,18)$. Another form of visfatin, nicotinamide phosphoribosyl transferase, is indispensable for myeloma cell growth and osteoclast activity, though its effect on MM cells requires further investigation (25). The present study revealed that the levels of visfatin were significantly higher in sera from patients with MM compared with sera from normal controls $(\mathrm{P}<0.05)$ but that there was no correlation between visfatin levels and the severity of MBD. 
A

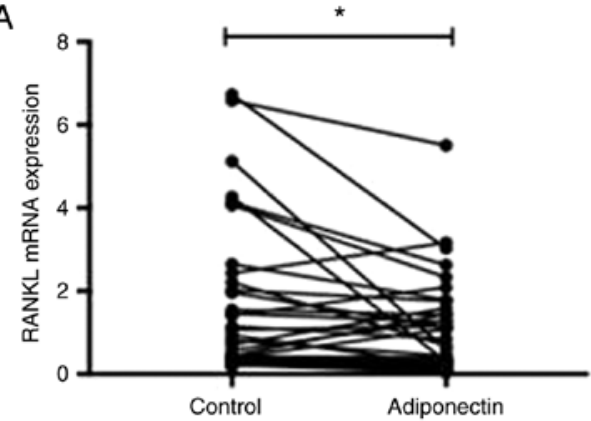

C

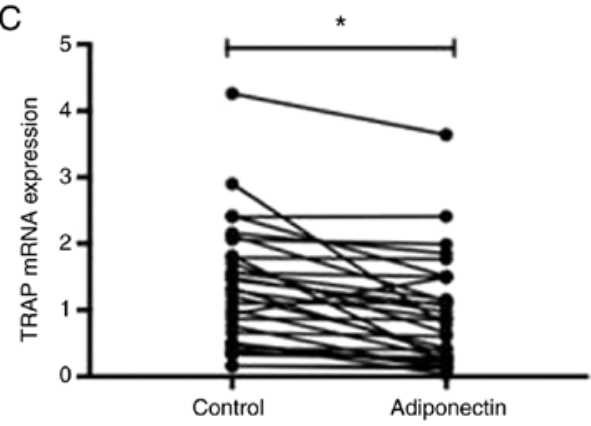

B

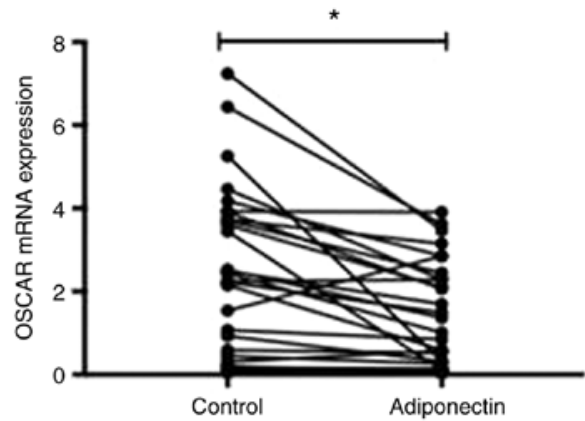

D

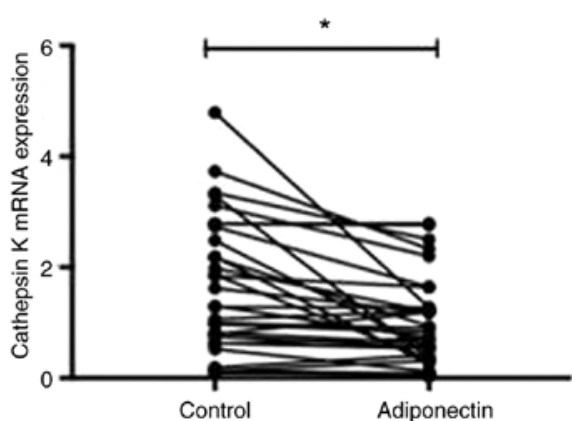

Figure 4. mRNA levels of the osteoclast-specific factors RANKL, OSCAR, TRAP and Cathepsin K. Expression levels of mRNA are presented for the control and adiponectin-treated group for (A) RANKL, (B) OSCAR, (C) TRAP and (D) Cathepsin K. "P<0.05 with comparisons shown by lines. RANKL, receptor activator of nuclear factor- $\mathrm{kB}$ ligand; OSCAR, osteoclast associated Ig-like receptor; TRAP, tartrate-resistant acid phosphatase.

A

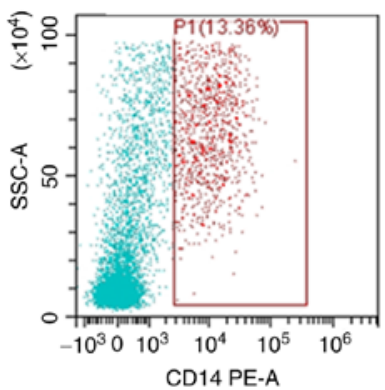

B

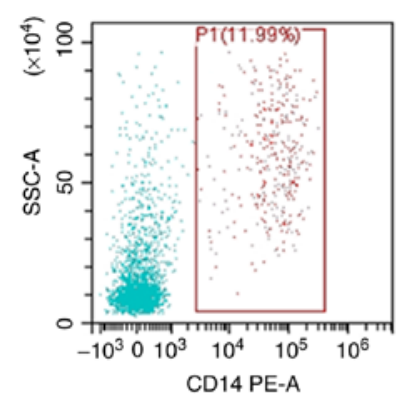

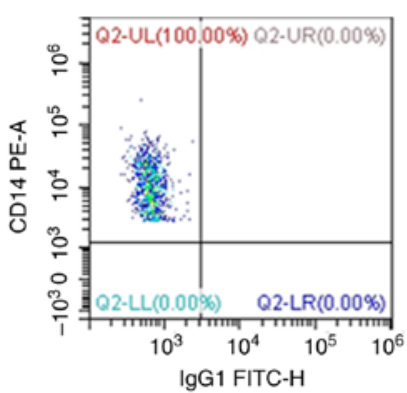
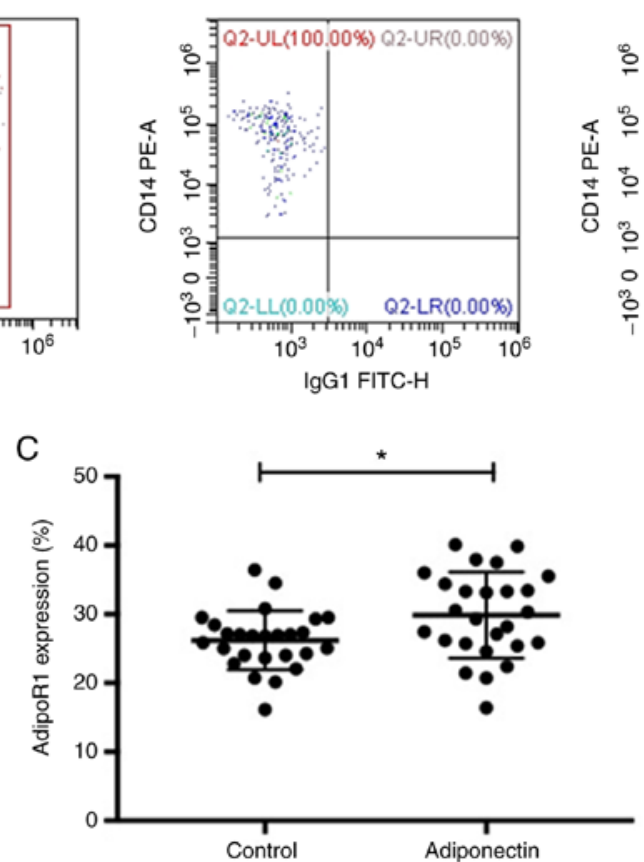
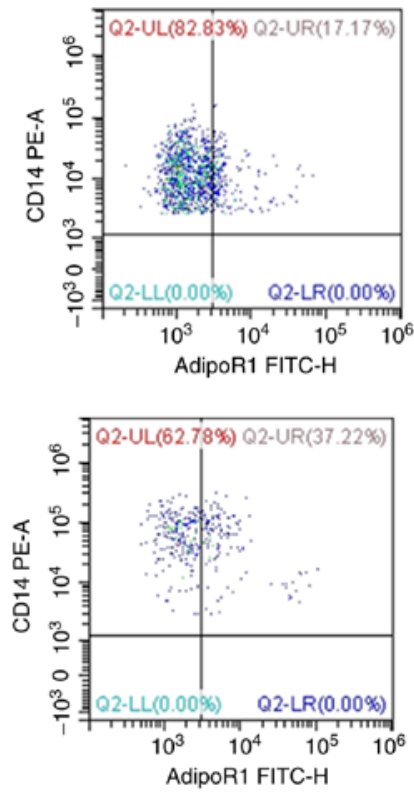

Figure 5. Adiponectin upregulates the AdipoR1 expression level. AdipoR1 levels in (A) the control group and (B) the adiponectin-treated group. (C) Quantification of the AdipoR1 levels in the two groups (26.21 44.27 vs. $29.86 \pm 6.23 \%)$. $\mathrm{P}<0.05$ with comparisons shown by lines. AdipoR1, adiponectin receptor 1. 

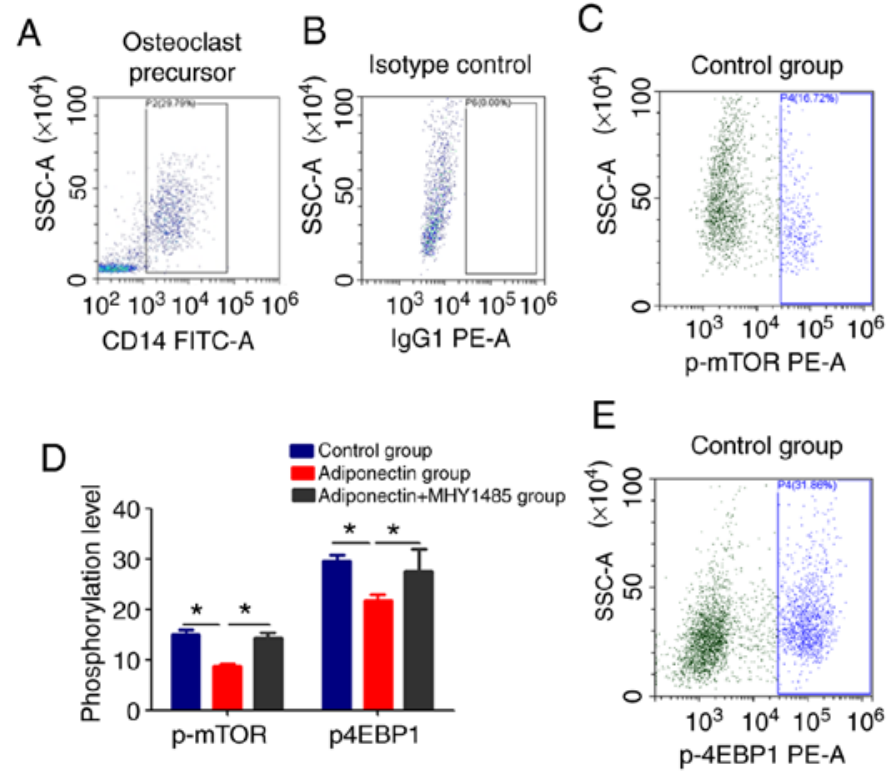
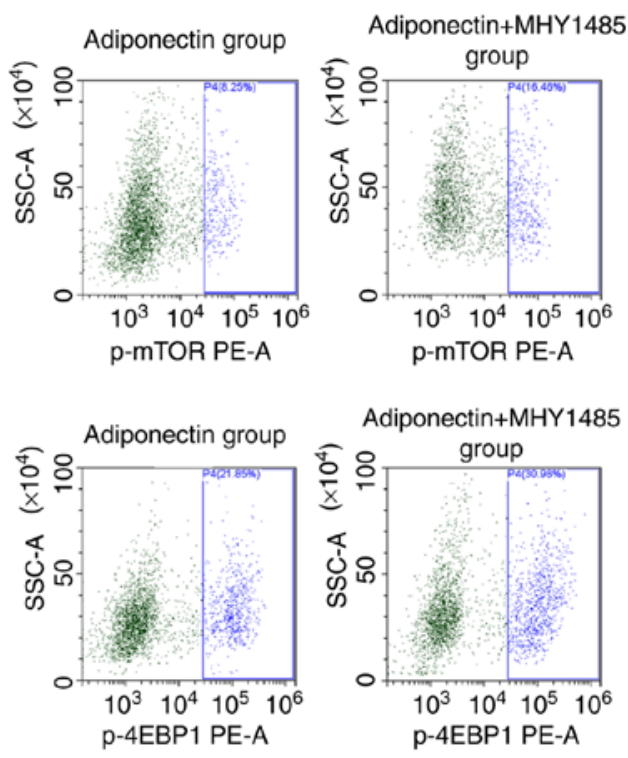

Figure 6. Phosphorylation levels of the mTOR pathway. (A) Osteoclast precursor was revealed to be CD14-positive. (B) Isotype control of p-mTOR and p-4EBP1 marked with IgG1-PE. (C) p-mTOR levels in the control group, adiponectin-treated group and adiponectin + MHY1485 group. (D) Histogram of the phosphorylation levels of the mTOR pathway. (E) p-4EBP1 levels in the control group, adiponectin-treated group and adiponectin $+\mathrm{MHY} 1485$ group. ${ }^{*} \mathrm{P}<0.05$ with comparisons shown by lines. mTOR, mechanistic target of rapamycin kinase; CD14, cluster of differentiation 14; p-, phosphorylated; 4EBP1, eukaryotic translation initiation factor 4E-binding protein; IgG1, immunoglobulin G1; PE, phycoerythrin.

Reseland et al (26) demonstrated that plasma concentration of leptin was significantly higher in newly diagnosed patients compared with a healthy control group. While the present study demonstrated that serum leptin levels in 39 patients with MM were not significantly different compared with those in normal controls, and no correlation existed between leptin levels and MM load or MBD. Further investigation is required to determine if the levels of leptin may affect MM cells.

Adiponectin is secreted not only by adipocytes but also by mesenchymal stem cells, osteoclasts and adipose cells in the bone marrow (27). Downregulation of adiponectin may increase the proliferation of MM cells in mouse models of disease (8). Dalamaga et al (28) demonstrated that lower levels of adiponectin predicted a higher risk of MM. In the present study, adiponectin levels were significantly lower in newly diagnosed patients with MM compared with in controls $(\mathrm{P}<0.05)$. Stage III patients had lower levels compared with stage I/II patients. In patients with MBD, adiponectin levels of stage $\mathrm{B} / \mathrm{C}$ patients were lower compared with those of stage A patients. These results are consistent with previous studies $(26,28)$. The present study observed a trend toward lower adiponectin levels in normal controls compared with patients with phase I/II MM or patients with stage A MM. Although these differences did not reach significance, the present study verified that the levels of adiponectin were negatively correlated with $\beta_{2}$-microglobulin, the percentage of plasma cells in the bone marrow and serum creatinine. A previous study demonstrated that the bone metabolic markers CTX, OC and PINP were useful for the diagnosis and monitoring of MBD (29). CTX is a marker of bone resorption, whereas OCN and PINP mark bone formation $(30,31)$. The present study determined the correlation among the levels of visfatin, leptin and adiponectin, and those of OCN, CTX and PINP. Adiponectin levels were negatively correlated with CTX and positively correlated with OCN. These results suggest that adiponectin is a protective factor for MBD. This is consistent with the observation that adiponectin may increase osteoblast proliferation and differentiation while inhibiting osteoclastogenesis in vitro (32). The present clinical results concur with the results of a previous study (32). The pathway through which these effects are mediated remains unclear, although previous studies have revealed that the adiponectin receptor AdipoR1 is present on osteoblasts and osteoclasts $(24,27)$. Further investigation will be required to elucidate the underlying mechanism.

Adiponectin has positive effects on insulin sensitivity, inflammation, oxidative stress and tumor growth $(33,34)$. In the present study, osteoclasts were successfully induced by RANKL and M-CSF subsequent to extracting mononuclear cells from patients with MM. TRAP staining revealed that the number of osteoclasts in the adiponectin group was lower compared with that in the control group. In addition, adiponectin decreased the mRNA levels of RANKL, OSCAR, TRAP and Cathepsin K, indicating that adiponectin may inhibit osteoclast differentiation and maturation in MM. The limitation of the present study is that only RT-qPCR was performed to assess the expression of osteoclast-specific factors RANKL, OSCAR, TRAP and Cathepsin K. Therefore, it is unclear whether the protein levels of these factors change in a similar manner, as western blot analysis was not performed due to the objective difficulty that the samples from the patients with MM were limited.

Adiponectin activates intracellular signaling through its receptors, AdipoR1 and AdipoR2, and the expression levels of these receptors correlate directly with the magnitude of the ensuing signaling (13). AdipoR1 is expressed at significantly higher levels in osteoclasts compared with AdipoR2, suggesting that AdipoR1 has a higher affinity for this receptor 
isoform (14). Thus, the present study did not measure the expression of AdipoR2. To examine how adiponectin affects osteoclast differentiation, the present study examined the effect of adiponectin on the cell surface expression of AdipoR1 on osteoclast precursors. The results revealed that the expression of AdipoR1 increased following adiponectin treatment, suggesting that adiponectin affects the differentiation and maturation of osteoclasts by increasing the expression of AdipoR1.

The molecular pathways downstream of AdipoR1 have not yet been fully elucidated. However, a number of studies have revealed that the mTOR signaling pathway, which is also associated with cell growth, is involved $(35,36)$. mTOR serves an important function in regulating cell proliferation, growth, differentiation, migration and survival (35-37). Phosphorylated AMPK inhibits mTOR signaling (29,32). 4EBP1 is a downstream molecule of mTOR and may be activated by phosphorylated mTOR. The phosphoinositide-3-kinase/protein kinase B/mTOR pathway serves an important function in regulating bone remodeling, which negatively regulates bone mineralization (35-38) in vitro and promotes osteoclastogenesis (39-41). Previous studies have revealed that the inhibition of $\mathrm{mTOR}$ signaling may reduce bone loss in patients with rheumatoid arthritis, multiple myeloma or neurofibromatosis (42-44). Adiponectin also may inhibit the growth of colorectal cancer cells by inhibiting the mTOR cell pathway (45). In the present study, it was revealed that adiponectin upregulates the expression of AdipoR1 on osteoclast precursor cells and inhibits the phosphorylation of mTOR and 4EBP1. Additionally, a mTOR signaling pathway-specific agonist (MHY1485) was used to further determine that the effects of adiponectin may be reversed. It revealed that adiponectin may inhibit osteoclast differentiation and maturation via the mTOR pathway. Therefore, adiponectin inhibits the differentiation of osteoclasts in MM and this effect may be mediated by the inhibition of mTOR signal transduction following the binding of adiponectin by its receptor. However, the specific molecular mechanism requires further investigation.

Adiponectin may serve a crucial function in MBD by inhibiting the differentiation and maturation of osteoclasts in patients with MM. This effect may be mediated by increasing the expression of AdipoR1 on the surface of osteoclast precursor cells through mTOR signaling.

\section{Acknowledgements}

Not applicable.

\section{Funding}

The present study was supported by the National Natural Science Foundation of China (grant nos. 81570106, 81400088, 81400085 and 81900131), the Tianjin Municipal Natural Science Foundation (grant nos. 14JCYBJC25400, 15JCYBJC24300, 15KG150, 16ZXMJSY00180 and 18JCQNJC80400), the Tianjin Education Commission Research Project (grant nos. 2018KJ045 and 2018KJ043) and The Youth Incubation Fund of Tianjin Medical University General Hospital (grant no. ZYYFY 2016006).

\section{Availability of data and materials}

All data generated or analyzed during this study are included in this published article.

\section{Authors' contributions}

ZL, HL and RF designed this research. ZL and YL performed the majority of the experiments, analyzed the data, drew the figures and drafted this manuscript. YW, RX and FM helped with cell culture, reverse transcription-quantitative PCR and the flow cytometry. CX performed the cell culture. All authors read and approved the final manuscript.

\section{Ethics approval and consent to participate}

The present study was ethically approved by the Ethics Committee of the Tianjin Medical University (Tianjin, China). Written informed consent was obtained from the patients.

\section{Patient consent for publication}

Written informed consent was obtained from the patients for the publication of this report and any accompanying images.

\section{Competing interests}

The authors declare that they have no competing interests.

\section{References}

1. Palumbo A and Anderson K: Multiple myeloma. N Engl J Med. 364: 1046-1060, 2011.

2. Aparicio T, Kotelevets L, Tsocas A, Laigneau JP, Sobhani I, Chastre $\mathrm{E}$ and Lehy T: Leptin stimulates the proliferation of human colon cancer cells in vitro but does not promote the growth of colon cancer xenografts in nude mice or intestinal tumorigenesis in Apc(Min/+) mice. Gut 54: 1136-1145, 2005.

3. Jardé T, Caldefie-Chézet F, Damez M, Mishellany F, Perrone D, Penault-Llorca F, Guillot J and Vasson MP: Adiponectin and leptin expression in primary ductal breast cancer and in adjacent healthy epithelial and myoepithelial tissue. Histopathology 53: 484-487, 2008.

4. Fenton JI, Birmingham JM, Hursting SD and Hord NG: Adiponectin blocks multiple signaling cascades associated with leptin-induced cell proliferation in Apc Min/+ colon epithelial cells. Int J Cancer 122: 2437-2445, 2008.

5. Mohammadi M, Zarghami N, Hedayati M, Ghaemmaghami S, Yamchi RM and Mohaddes M: Visfatin effects on telomerase gene expression in AGS gastric cancer cell line. Indian J Cancer 52: 32-35, 2015.

6. Hofmann JN, Liao LM, Pollak MN, Wang Y, Pfeiffer RM, Baris D, Andreotti G, Lan Q, Landgren O, Rothman N and Purdue MP: A prospective study of circulating adipokine levels and risk of multiple myeloma. Blood 120: 4418-4420, 2012.

7. Medina EA, Oberheu K, Polusani SR, Ortega V, Velagaleti GV and Oyajobi BO: PKA/AMPK signaling in relation to adiponectin's antiproliferative effect on multiple myeloma cells Leukemia 28: 2080-2089, 2014.

8. Fowler JA, Lwin ST, Drake MT, Edwards JR, Kyle RA, Mundy GR and Edwards CM: Host-derived adiponectin is tumor-suppressive and a novel therapeutic target for multiple myeloma and the associated bone disease. Blood 118: 5872-5882, 2011.

9. Teitelbaum SL and Ross FP: Genetic regulation of osteoclast development and function. Nat Rev Genet 4: 638-649, 2003.

10. Boyle WJ, Simonet WS and Lacey DL: Osteoclast differentiation and activation. Nature 423: 337-342, 2003.

11. Massey HM and Flanagan AM: Human osteoclasts derive from CD14-positive monocytes. Br J Haematol 106: 167-170, 1999. 
12. Kim MS, Day CJ and Morrison NA: MCP-1 is induced by receptor activator of nuclear factor- $\{\mathrm{kappa}\} \mathrm{B}$ ligand, promotes human osteoclast fusion, and rescues granulocyte macrophage colony-stimulating factor suppression of osteoclast formation. J Biol Chem 280: 16163-16169, 2005.

13. Yamauchi T, Kamon J, Ito Y, Tsuchida A, Yokomizo T, Kita S, Sugiyama T, Miyagishi M, Hara K, Tsunoda M, et al: Cloning of adiponectin receptors that mediate antidiabetic metabolic effects. Nature 423: 762-769, 2003.

14. Pacheco-Pantoja EL, Waring VJ, Wilson PJ, Fraser WD and Gallagher JA: Adiponectin receptors are present in RANK-L-induced multinucleated osteoclast-like cells. J Recept Signal Transduct Res 33: 291-297, 2013.

15. Gan ZY, Fitter S, Vandyke K, To LB, Zannettino AC and Martin SK: The effect of the dual PI3K and mTOR inhibitor BEZ235 on tumour growth and osteolytic bone disease in multiple myeloma. Eur J Haematol 94: 343-354, 2015.

16. Walker S, Wankell M, Ho V, White R, Deo N, Devine C, Dewdney B, Bhathal P, Govaere O, Roskams T, et al: Targeting mTOR and Src restricts hepatocellular carcinoma growth in a novel murine liver cancer model. PLoS One 14: e0212860, 2019.

17. Rajkumar SV, Harousseau JL, Durie B, Anderson KC, Dimopoulos M, Kyle R, Blade J, Richardson P, Orlowski R, Siegel D, et al: Consensus recommendations for the uniform reporting of clinical trials: Report of the international myeloma workshop consensus panel 1. Blood 117: 4691-4695, 2011.

18. Terpos E, de la Fuente J, Szydlo R, Hatjiharissi E, Viniou N, Meletis J, Yataganas X, Goldman JM and Rahemtulla A: Tartrate-resistant acid phosphatase isoform 5b: A novel serum marker for monitoring bone disease in multiple myeloma. Int J Cancer 3: 455-457, 2003.

19. Greipp PR, San Miguel J, Durie BG, Crowley JJ, Barlogie B, Bladé J, Boccadoro M, Child JA, Avet-Loiseau H, Kyle RA, et al: International staging system for multiple myeloma. J Clin Oncol 23: 3412-3420, 2005

20. Warhurst G, Dunn G, Chadwick P, Blackwood B, McAuley D, Perkins GD, McMullan R, Gates S, Bentley A, Young D, et al: Rapid detection of health-care-associated bloodstream infection in critical care using multipathogen real-time polymerase chain reaction technology: A diagnostic accuracy study and systematic review. Health Technol Assess 19: 1-142, 2015

21. Sonzogni-Desautels K, Di Lenardo TZ, Renteria AE, Gascon MA, Geary TG and Ndao M: A protocol to count cryptosporidium oocysts by flow cytometry without antibody staining. PLoS Negl Trop Dis 13: e0007259, 2019.

22. Sorensen MG, Henriksen K, Schaller S, Henriksen DB, Nielsen FC, Dziegiel MH and Karsdal MA: Characterization of osteoclasts derived from CD14+ monocytes isolated from peripheral blood. J Bone Miner Metab 25: 36-45, 2007.

23. Tong X, Gu J, Song R, Wang D, Sun Z, Sui C, Zhang C, Liu X, Bian J and Liu Z: Osteoprotegerin inhibit osteoclast differentiation and bone resorption by enhancing autophagy via AMPK/mTOR/p70S6K signaling pathway in vitro. J Cell Biochem 6: 27468, 2018.

24. Birmann BM, Giovannucci E, Rosner B, Anderson KC and Colditz GA: Body mass index, physical activity, and risk of multiple myeloma. Cancer Epidemiol Biomarkers Prev 16: 1474-1478, 2007.

25. Morris EV and Edwards CM: Adipokines, adiposity, and bone marrow adipocytes: Dangerous accomplices in multiple myeloma. J Cell Physiol 233: 9159-9166, 2018.

26. Reseland JE, Reppe S, Olstad OK, Hjorth-Hansen H, Brenne AT, Syversen U, Waage A and Iversen PO: Abnormal adipokine levels and leptin-induced changes in gene expression profiles in multiple myeloma. Eur J Haematol 83: 460-470, 2009.

27. Berner HS, Lyngstadaas SP, Spahr A, Monjo M, Thommesen L, Drevon CA, Syversen U and Reseland JE: Adiponectin and its receptors are expressed in bone-forming cells. Bone 35: 842-849, 2004.

28. Dalamaga M, Karmaniolas K, Panagiotou A, Hsi A, Chamberland J, Dimas C,Lekka A and Mantzoros CS: Low circulating adiponectin and resistin, but not leptin, levels are associated with multiple myeloma risk: A case-control study. Cancer Causes Control 20 193-199, 2009.

29. Peng F, Fu R, Liu H, Wang Y, Ding K, Ding S, Liu Z, Ruan E, $\mathrm{Qu} \mathrm{W}$, Wang $\mathrm{H}$, et al: Clinical significance of serum bone metabolic markers in diagnosis and monitoring of myeloma bone disease. Zhonghua Yi Xue Za Zhi 95: 3436-3439, 2015 (In Chinese)
30. Vasikaran S, Cooper C, Eastell R, Griesmacher A, Morris HA, Trenti $\mathrm{T}$ and Kanis JA: International osteoporosis foundation and international federation of clinical chemistry and laboratory medicine position on bone marker standards in osteoporosis. Clin Chem Lab Med 49: 1271-1274, 2011.

31. Terpos E, Dimopoulos MA, Sezer O, Roodman D, Abildgaard N, Vescio R, Tosi P, Garcia-Sanz R, Davies F, Chanan-Khan A, et al: The use of biochemical markers of bone remodeling in multiple myeloma: A report of the international myeloma working group. Leukemia 24: 1700-1712, 2010.

32. Oshima K, Nampei A, Matsuda M, Iwaki M, Fukuhara A, Hashimoto J, Yoshikawa $\mathrm{H}$ and Shimomura I: Adiponectin increases bone mass by suppressing osteoclast and activating osteoblast. Biochem Biophys Res Commun 331: 520-526, 2005.

33. Kadowaki T, Yamauchi T, Kubota N, Hara K, Ueki K and Tobe K: Adiponectin and adiponectin receptors in insulin resistance, diabetes, and the metabolic syndrome. J Clin Invest 116: 1784-1792, 2006.

34. Nakayama S, Miyoshi Y, Ishihara H and Noguchi S: GrowthInhibitory effect of adiponectin via adiponectin receptor 1 on human breast cancer cells through inhibition of S-phase entry without inducing apoptosis. Breast Cancer Res Treat 112: 405-410, 2008.

35. Ogawa T, Tokuda M, Tomizawa K, Matsui H, Itano T, Konishi R, Nagahata $\mathrm{S}$ and Hatase $\mathrm{O}$ : Osteoblastic differentiation is enhanced by rapamycin in rat osteoblast-like osteosarcoma (ROS 17/2.8) cells. Biochem Biophys Res Commun 249: 226-230, 1998.

36. Viñals F, López-Rovira T, Rosa JL and Ventura F: Inhibition of $\mathrm{PI} 3 \mathrm{~K} / \mathrm{p} 70 \mathrm{~S} 6 \mathrm{~K}$ and p38 MAPK cascades increases osteoblastic differentiation induced by BMP-2. FEBS Lett 510: 99-104, 2002.

37. Oldham S and Hafen E: Insulin/IGF and target of rapamycin signaling: A TOR de force in growth control. Trends Cell Biol 13: 79-85, 2003.

38. Lee KW, Yook JY, Son MY, Kim MJ, Koo DB, Han YM and Cho YS: Rapamycin promotes the osteoblastic differentiation of human embryonic stem cells by blocking the mTOR pathway and stimulating the BMP/Smad pathway. Stem Cells Dev 19: 557-568, 2010.

39. Lee SE, Woo KM, Kim SY, Kim HM, Kwack K, Lee ZH and Kim HH: The phosphatidylinositol 3-kinase, p38, and extracellular signal-regulated kinase pathways are involved in osteoclast differentiation. Bone 30: 71-77, 2002.

40. Sugatani T and Hruska KA: Akt1/Akt2 and mammalian target of rapamycin/Bim play critical roles in osteoclast differentiation and survival, respectively, whereas Akt is dispensable for cell survival in isolated osteoclast precursors. J Biol Chem 280: 3583-3589, 2005.

41. Glantschnig H, Fisher JE, Wesolowski G, Rodan GA and Reszka AA: M-CSF, TNFalpha and RANK ligand promote osteoclast survival by signaling through $\mathrm{mTOR} / \mathrm{S} 6$ kinase. Cell Death Differ 10: 1165-1177, 2003.

42. Kloos B, Chakraborty S, Lindner SG, Noack K, Harre U, Schett G, Krämer OH and Kubatzky KF: Pasteurella multocida toxin-induced osteoclastogenesis requires mTOR activation. Cell Commun Signal 13: 40, 2015.

43. Bertoldo F, Silvestris F, Ibrahim T, Cognetti F, Generali D, Ripamonti CI, Amadori D, Colleoni MA, Conte P, Del Mastro L, et al: Targeting bone metastatic cancer: Role of the mTOR pathway. Biochim Biophys Acta 1845: 248-254, 2014.

44. Hadji P, Coleman R and Gnant M: Bone effects of mammalian target of rapamycin (mTOR) inhibition with everolimus. Crit Rev Oncol Hematol 87: 101-111, 2013.

45. Sugiyama M, Takahashi H, Hosono K, Endo H, Kato S, Yoneda K, Nozaki Y, Fujita K, Yoneda M, Wada K, et al: Adiponectin inhibits colorectal cancer cell growth through the AMPK/mTOR pathway. Int J Oncol 34: 339-344, 2009.

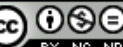

This work is licensed under a Creative Commons Attribution-NonCommercial-NoDerivatives 4.0 International (CC BY-NC-ND 4.0) License. 